\title{
Polycystic ovary syndrome: reviewing diagnosis and management of metabolic disturbances
}

\author{
Síndrome dos ovários policísticos: revisando o \\ diagnóstico e o manejo dos distúrbios metabólicos
}

Poli Mara Spritzer ${ }^{1}$

Gynecologic Endocrinology Unit, Division of Endocrinology, Hospital de Clínicas de Porto Alegre (HCPA): Brazil and Laboratory of Molecular Endocrinology, Department of Physiology, Universidade Federal do Rio Grande do Sul (UFRGS), Porto Alegre, RS, Brazil
Correspondence to: Poli Mara Spritzer Division of Endocrinology, Hospital de Clínicas de Porto Alegre Rua Ramiro Barcelos, 2350 90035-003 - Porto Alegre, RS, Brazil spritzer@ufrgs.br

Received on Oct/9/2013 Accepted on Nov/26/2013

\begin{abstract}
Polycystic ovary syndrome (PCOS) is a common condition in women at reproductive age associated with reproductive and metabolic dysfunction. Proposed diagnosed criteria for PCOS include two out of three features: androgen excess, menstrual irregularity, and polycystic ovary appearance on ultrasound (PCO), after other causes of hyperandrogenism and dysovulation are excluded. Based on these diagnostic criteria, the most common phenotypes are the "classic PCOS" - hyperandrogenism and oligomenorrhea, with or without PCO; the "ovulatory phenotype" - hyperandrogenism and PCO in ovulatory women; and the "non-hyperandrogenic phenotype", in which there is oligomenorrhea and PCO, without overt hyperandrogenism. The presence of obesity may exacerbate the metabolic and reproductive disorders associated with the syndrome. In addition, PCOS women present higher risk for type 2 diabetes and higher prevalence of cardiovascular risk factors that seems to be associated with the classic phenotype. The main interventions to minimize cardiovascular and metabolic risks in PCOS are lifestyle changes, pharmacological therapy, and bariatric surgery. Treatment with metformin has been shown to improve insulin sensitivity, lowering blood glucose and androgen levels. These effects are more potent when combined with lifestyle interventions. In conclusion, besides reproductive abnormalities, PCOS has been associated to metabolic comorbidities, most of them linked to obesity. Confounders, such as the lack of standard diagnostic criteria, heterogeneity of the clinical presentation, and presence of obesity, make management of PCOS difficult. Therefore, the approach to metabolic abnormalities should be tailored to the risks and treatment goals of each individual woman. Arq Bras Endocrinol Metab. 2014;58(2):182-7
\end{abstract}

Keywords

PCOS; obesity; insulin resistance; metformin

\section{RESUMO}

A síndrome dos ovários policísticos (PCOS) é um distúrbio frequente em mulheres em idade reprodutiva, associado com disfunção reprodutiva e metabólica. Os critérios diagnósticos atuais para PCOS incluem pelo menos dois dos três seguintes: hiperandrogenismo, irregularidade menstrual e aparência policística dos ovários à ultrassonografia (PCO), após exclusão de outras causas de hiperandrogenismo e anovulação. Com base nesses critérios diagnósticos, os fenótipos mais comuns são "PCOS clássico" - hiperandrogenismo e oligomenorreia, com ou sem PCO; o "fenótipo ovulatório" - hiperandrogenismo e PCO em mulheres ovulatórias; e o "fenótipo não hiperandrogênico"- no qual ocorrem oligomenorreia e PCO sem hiperandrogenismo evidente. A presença de obesidade pode exacerbar os distúrbios metabólicos e reprodutivos associados com a síndrome. Além disso, mulheres com PCOS apresentam maior risco para diabetes tipo 2 e maior prevalência de fatores de risco cardiovascular, que parecem estar associados com o fenótipo clássico. As principais intervenções para minimizar riscos metabólicos e cardiovasculares em PCOS são mudanças de estilo de vida, tratamento farmacológico e cirurgia bariátrica. 0 tratamento com metformina melhora a sensibilidade à insulina, reduz a glicemia e os níveis de androgênios. Esses efeitos são mais evidentes quando a metformina é associada às mudanças de estilo de vida. Em conclusão, além das anormalidades reprodutivas, a PCOS tem sido associada com comorbidades metabólicas ligadas à obesidade. Fatores confundidores, como a falta de critérios diagnósticos padronizados, heterogeneidade da apresentação clínica e presença de obesidade, tornam difícil o manejo clínico de PCOS. Assim, a abordagem das anormalidades metabólicas deve ser individualizada para os riscos e objetivos terapêuticos de cada mulher. Arq Bras Endocrinol Metab. 2014;58(2):182-7

\section{Descritores}

PCOS; obesidade; resistência insulínica; metformina 


\section{INTRODUCTION}

$\mathrm{P}$ olycystic ovary syndrome (PCOS) is the most common endocrine disease affecting women of reproductive age. The prevalence of PCOS varies according to the diagnostic criteria used, with estimates ranging from $9 \%$ in women of reproductive age, according to $\mathrm{NIH}$ criteria, up to $18 \%$, with the Rotterdam criteria (1-3).

PCOS is a multifactorial disease, and the individual susceptibility is probably determined by multiple genetic and environmental risk factors. It is primarily characterized by ovulatory dysfunction and hyperandrogenism $(1,2)$, but the clinical presentation is heterogeneous and patients may present some of various signs and symptoms (Table 1). This heterogeneity seems to be modulated by multiple factors, such as prenatal androgen exposure, nutritional status in the uterus, genetic factors, as well as ethnicity, insulin resistance of puberty and/or exaggerated adrenarche and changes in body weight (4-6). Environmental factors, such as obesity, appear to exacerbate the underlying genetic predisposition. Concerning ethnicity, the presence of hirsutism is less frequent in Asian patients (around 10\%), compared to Caucasian ones $(70 \%)(1,6)$.

Hirsutism is defined as a score of 8 or more on the modified Ferriman-Gallwey index (7). Oligo/amenorrheic cycles are defined as 8 or less cycles per year and biochemical androgen determinations should be performed in the follicular phase in patients with preserved menstrual cycles.

Table 1. Clinical presentation of PCOS

Hirsutism, acne, alopecia

Irregular menstrual cycles, oligomenorrhea, amenorrhea

Ovulatory dysfunction and infertility

Increased risk for T2 diabetes, dyslipidemia, hypertension

\section{DIAGNOSTIC CRITERIA}

Proposed diagnosed criteria for PCOS include the NIH Consensus (8), defined, in 1990, as the presence of clinical and/or biochemical hyperandrogenism and oligomenorrhea/anovulation (Table 2). Later, in 2003, the Rotterdam Consensus (9) introduced the polycystic ovary appearance (PCO) on ultrasound as a new criterion to be added to the two previous criteria of the $\mathrm{NIH}$, and the diagnosis requires two out of these three criteria. In turn, the Androgen Excess and PCOS Society (10) considered that androgen excess is a central event in the pathogenesis and development of PCOS, and established that this criterion should be present and accompanied by one of the others: oligomenorrhea and/or PCO (Table 2). In all cases, exclusion of other androgen excess disorders, such as non-classical congenital adrenal hyperplasia (NC-CAH), Cushing's syndrome, androgen-secreting tumors, hyperprolactinemia, thyroid diseases, drug-induced androgen excess should be excluded, as well as other causes of oligomenorrhea or anovulation.

Table 2. Diagnostic criteria for PCOS

\begin{tabular}{lll}
\hline $\begin{array}{l}\text { NIH Consensus 1990 } \\
\text { (all required) }\end{array}$ & $\begin{array}{c}\text { Rotterdam } \\
\text { Consensus 2003 } \\
\text { (two out of three } \\
\text { required) }\end{array}$ & $\begin{array}{c}\text { AEPCOS definition } \\
\text { 2006 } \\
\text { (androgen excess and } \\
\text { one other criterion) }\end{array}$ \\
\hline $\begin{array}{l}\text { Clinical and/or } \\
\text { biochemical }\end{array}$ & $\begin{array}{l}\text { Clinical and/or } \\
\text { biochemical }\end{array}$ & $\begin{array}{l}\text { Clinical and/or } \\
\text { biochemical }\end{array}$ \\
hyperandrogenism & hyperandrogenism & $\begin{array}{l}\text { hyperandrogenism } \\
\text { Oligo/amenorrhea, }\end{array}$ \\
Onovulation & $\begin{array}{l}\text { Oligo/amenorrhea, } \\
\text { anovulation }\end{array}$ & $\begin{array}{l}\text { Oligomenorrhea, } \\
\text { anovulation }\end{array}$ \\
& $\begin{array}{l}\text { Polycystic ovaries } \\
\text { appearance on }\end{array}$ & $\begin{array}{l}\text { Polycystic ovaries } \\
\text { appearance on } \\
\text { ultrasound }\end{array}$ \\
\hline
\end{tabular}

Exclusion of other androgen excess disorders: NC-CAH, Cushing's syndrome, androgen secreting tumors, hyperprolactinemia, thyroid diseases, drug-induced androgen excess. Other causes for anovulation should also been excluded.

In consequence, new phenotypes have arisen in addition to the classic phenotype, in which patients present hyperandrogenism and oligomenorrhea with or without PCO on ultrasound. These new phenotypes are the "ovulatory phenotype", which means hyperandrogenism and PCO in an ovulatory woman, and the "non-hyperandrogenic phenotype", in which there is oligomenorrhea and PCO, without overt hyperandrogenism.

PCO has been defined as the presence of 12 or more follicles of 2-9 $\mathrm{mm}$ or ovarian volume greater than $10 \mathrm{~cm}^{3}(9)$. However, with the new equipment, it is possible to visualize and count small follicles of less than $2 \mathrm{~mm}$ nowadays (11). Therefore, the consequence of the improved ovarian imaging is the revaluation of the current follicle number threshold, and the probable increase in the number of follicles to more than 19-26 follicles per ovary and per age classes to better define PCOS $(11,12)$. Anti-Müllerian Hormone (AMH) levels are correlated with follicle counts and its measurement has been useful for screening and prognosis of reproductive issues. The determination of an AMH cutoff value is still lacking, but may become an additional tool to define PCO and PCOS phenotypes in the near future (11-13). 
In turn, morphological ovarian changes are not exclusive of PCOS, and the presence of PCO in nonhirsute women with normal cycles is not negligible, varying from 2.5 to $33 \%$ in different studies $(10,14)$. In addition, while the inclusion of a non-hyperandrogenic phenotype of the diagnosis of PCOS is still controversial, some authors consider the presence of $\mathrm{PCO}$ as being itself a sign of hyperandrogenism.

Recently, an Expert Panel from a NIH EvidenceBased Methodology Workshop on PCOS reinforced the use of the wider Rotterdam Criteria to diagnose the Syndrome. Therefore, the prevalence of PCOS is now greater than before when using the NIH criteria (15). Classic PCOS is the most common phenotype, with a prevalence of around $70 \%$, with the ovulatory and the non-androgenic phenotypes sharing the other $30 \%$ of prevalence $(1,3,13)$.

Clinical characterization also changes throughout the lifespan, especially during the post-menarche years and in the menopause transition.

\section{DEFINITION AND PREVALENCE OF PCOS IN ADOLESCENT GIRLS}

PCOS is a persistent challenge to the clinician, as the phenotype of the syndrome can vary widely. This is still more evident during the post-pubertal period, as signs and symptoms of PCOS overlap with normal puberty. There is a relatively high rate of menstrual irregularity and anovulatory cycles in this period, as well as some difficulties in interpreting clinical and biochemical evidence of hyperandrogenism: acne is a very common complaint during adolescence, alopecia is a rare phenomenon in girls, and hirsutism is sometimes borderline and aggravates slowly.

Uncertainty also regards the significance of polycystic ovarian morphology on ultrasound: microcysts are often seen even before menarche. In a previous study with normal girls from 1 to 13 years old, we have shown the presence of paucicystic ovaries on ultrasound (up to five follicles measuring less than $10 \mathrm{ml}$ ) in $7 \%$ of girls before puberty and in $18 \%$ of girls with telarche. The prevalence of multicystic ovaries (more than six follicles measuring less than $10 \mathrm{~mL}$ ) was found in $9 \%$ of girls 12 and 13 years with initial puberty (16). In contrast, ovary volume greater than $10 \mathrm{~mL}$ seems to be a better marker of PCOS in adolescent girls presenting hyperandrogenism and oligo/amenorrhea for at least 2 years post-menarche $(17,18)$.
Because of these uncertainties, and the fact that the majority of ultrasound examinations in adolescent girls is abdominal and not transvaginal, the diagnosis of PCOS in adolescents needs all three Rotterdam criteria, and not only two (13). Therefore, for the diagnosis of PCOS in adolescent girls, one should consider: 1) oligo/amenorrhea at least 2 years post-menarche or primary amenorrhea at age 16 years; 2) PCO morphology including increased ovarian volume $\left.\left(>10 \mathrm{~cm}^{3}\right) ; 3\right)$ biochemical hyperandrogenemia, and not only clinical hyperandrogenism. However, even if the diagnosis cannot be confirmed and needs to be postponed, individual manifestations (hirsutism, irregular menses) should be treated.

\section{PCOS IN MENOPAUSAL TRANSITION AND POST- MENOPAUSE: ARE THERE SPECIFIC FEATURES?}

In menopausal transition, there may be an amelioration of clinical features. In fact, there is a trend towards more regular cycles and improvement on hirsutism with aging (19). This is in part due to the well-known decrease in androgen secretion from the third for the fifth decade of life that occurs in normal women (20), and has been also reported in PCOS $(13,19,21)$. In addition, ovarian volume decreases along with premenopause and menopause transition, as previously reported (22). Thus, alterations in ovarian volume and morphology may be less evident in PCOS during menopausal transition, and PCO criteria are not useful after menopause.

In fact, no specific clinical presentation during menopause has been established, and the diagnosis of PCOS is, in general, confirmed before this period, based on the history of oligomenorrhea and hyperandrogenism. Additionally, clinical or biochemical hyperandrogenism appearing in previously normal peri- or post-menopausal women should be carefully investigated in order to screen them for androgen-secreting tumors.

\section{OBESITY, INSULIN RESISTANCE AND METABOLIC COMORBIDITIES}

Obesity is a prevalent characteristic of PCOS $(9,23)$, ranging from $12.5 \%(24)$ to $100 \%(25)$, with a pooled estimated prevalence of $49 \%(26)$, as shown by a recent meta-analysis (27). The presence of obesity may exacerbate the metabolic and reproductive disorders 
associated with the syndrome (28), including insulin resistance, dyslipidemia, and metabolic syndrome $(23,29$ 31). A meta-analysis (32) has shown that women with PCOS have higher levels of triglycerides (TG), LDLcholesterol and total cholesterol (TC), and lower HDLcholesterol levels compared with control women, regardless of body mass index (BMI). In addition, PCOS women present higher risk for type 2 diabetes $(13,14)$. PCOS is also associated with a clustering of cardiovascular risk factors $(10,13,29,33,34)$. However, there is no definitive evidence for increased cardiovascular events, nor data showing that PCOS alone leads to increased cardiovascular risk independent of associated risk factors. In fact, more rigorous cohort studies of long-term cardiovascular outcomes and clinical trials of risk factor modification are required for women with PCOS.

In addition, evidence suggests clinical phenotypes are related with different metabolic risks (Table 3 ). In this sense, insulin resistance seems to be a specific feature of the classic phenotype and, to a lesser extent, of the ovulatory phenotype $(29,35,36)$. Non-hyperandrogenic phenotype behave as a separate group that is metabolically similar to non-PCOS women $(15,32)$.

Table 3. Clinical features of different phenotypes

\begin{tabular}{lll}
\hline Classic PCOS & Ovulatory PCOS & $\begin{array}{c}\text { PCOS without } \\
\text { hyperandrogenism }\end{array}$ \\
\hline $\begin{array}{l}\text { Hyperandrogenism and } \\
\text { anovulation with or } \\
\text { without PCO }\end{array}$ & $\begin{array}{l}\text { Hyperandrogenism and } \\
\text { PCO }\end{array}$ & Anovulation and PCO \\
$\begin{array}{l}\text { More severe menstrual } \\
\text { disturbances and } \\
\text { hyperandrogenism }\end{array}$ & $\begin{array}{l}\text { Lesser degrees of } \\
\text { hyperandrogenism }\end{array}$ & $\begin{array}{l}\text { Minor menstrual } \\
\text { irregularity }\end{array}$ \\
$\begin{array}{l}\text { Higher prevalence of } \\
\text { total and abdominal } \\
\text { obesity and metabolic } \\
\text { syndrome }\end{array}$ & $\begin{array}{l}\text { Lower prevalence of } \\
\text { metabolic syndrome }\end{array}$ & $\begin{array}{l}\text { Metabolic profile often } \\
\text { aimilar to normal women }\end{array}$ \\
Higher prevalence of & dyslipidemia & \\
T2DM and & & \\
cardiovascular risk & & \\
factors & & \\
\hline
\end{tabular}

\section{MANAGEMENT OF METABOLIC DISTURBANCES}

Insulin resistance (and compensatory hyperinsulinemia) is an important factor in maintaining hyperandrogenemia by acting directly on theca cells inducing excess androgen production. Insulin also acts as a cogonadotropin, increasing the effect of $\mathrm{LH}$ on ovarian androgen secretion. In consequence, both insulin and androgens act on the liver inhibiting SHBG secretion, leading to increased free and bioactive androgen circulating levels and making clinical hyperandrogenism worse. In addition, insulin resistance plays a central role on the pathophysiology of metabolic syndrome and on the cardiovascular risk in PCOS women.

However, insulin resistance is a common, but not universal feature of PCOS, and treatment should be directed to the consequences rather than to insulin resistance per se (37). These consequences are metabolic syndrome; clinical features shown to improve with insulin-sensitizing drugs, such as acanthosis nigricans; total and abdominal adiposity, as well as impaired fasting glucose (IFG, fasting glucose equal or higher than 100 $\mathrm{mg} / \mathrm{dL}$ ); impaired glucose tolerance (IGT, 2 h postglucose equal or higher than $140 \mathrm{mg} / \mathrm{dL}$ ); and type 2 diabetes (T2DM) $(37,38)$.

The main interventions to minimize cardiovascular and metabolic risks in PCOS are lifestyle changes, pharmacological therapy, and bariatric surgery (Table 4). Lifestyle modification is the first form of therapy combining behavioral (reduction of psychosocial stressors), dietary, and exercise management. Frequently, however, it will be necessary to add an insulin-sensitizing drug (ISD) to the treatment. Metformin and thiazolidinediones (pioglitazone) are the main available ISD. However, due to the eventual weight gain and cancer risks of thiazolidinediones, the prescription of these drugs has been limited to diabetic patients and will not be discussed here.

Table 4. Treatment of metabolic comorbidities in PCOS

Non pharmacological interventions
Physical activity
Diet and lifestyle changes
Insulin sensitizing drugs
Metformin
Specific treatment for diabetes, hypertension, dyslipidemia and obesity
Bariatric surgery

Metformin, a biguanide, has been widely used for PCOS patients, and evidence indicates it is beneficial for women with PCOS with metabolic syndrome and/ or obesity, as well as for affected women who have impaired glucose tolerance, since the efficacy of metformin for diabetes prevention has been demonstrated in individuals with pre-diabetes (38). Its main action is in the liver, with suppression of gluconeogenesis and hepatic glucose output, but it also enhances peripheral insulin action, and reduces glucose absorption from the 
digestive tract, with no significant direct effect on pancreatic insulin production (39). Metformin also directly inhibits thecal androgen production (40).

In women with PCOS, treatment with metformin has been shown to ameliorate the cardiometabolic profile by improving insulin sensitivity, lowering blood glucose and androgen levels and possibly by its effects on body weight (41-44). These effects of metformin are more potent when it is combined with lifestyle intervention (41). Diets with low caloric intake are part of the treatment and those with low glycemic index appear to be better adjusted for PCOS patients $(26,43)$.

It is important to underscore, however, that the first-line treatment for hirsutism, menstrual irregularities and infertility are anti-androgens, contraceptive steroids, and clomiphene citrate, respectively. While metformin is more effective than oral contraceptives in reducing fasting insulin and not increasing triglycerides, it is less effective in improving menstrual pattern, hirsutism or decreasing testosterone (45). Importantly, there is no evidence of benefits in the absence of insulin resistance.

Metformin is also a reasonable treatment option for those women to whom oral contraceptives may not be recommended, such as PCOS patients presenting moderate to severe high blood pressure, high triglycerides levels, class II or III obesity and/or metabolic syndrome. In this case, and especially if antiandrogen drugs are added to the treatment, other options for contraception should be recommended, including progestogen-only pills (mini-pill) or IUDs.

The usual dose of metformin for PCOS is 1,500 to 2,500 mg per day. A main limitation can be side effects, which are predominantly gastroenterological, consisting of abdominal discomfort, nausea, and diarrhea. These symptoms are usually dose-dependent and can be minimized by gradually increasing the dose of metformin over a period of 1-2 months. Initial doses should be $250-500 \mathrm{mg} /$ day, taken just before the main meal. In the case gastrointestinal side effects recidivate, the current dose may be reduced for a period of 7-10 days, followed by a resumption of the dosage increase. Hepatic and renal function should be monitored before and during treatment.

Specific additional treatment for high blood pressure, dyslipidemia or obesity may be needed for individual PCOS women. Additionally, bariatric surgery may be another option for severe obesity or obesity with metabolic comorbidities $(13,46)$.
In conclusion, besides reproductive abnormalities, PCOS has been associated to metabolic comorbidities, most of them, but not all, linked to obesity. Confounders, such as the lack of standard diagnostic criteria, the heterogeneity of the clinical presentation, and the presence of obesity, make the management of PCOS difficult. Therefore, the approach to metabolic abnormalities should be tailored to the risks and treatment goals of each individual woman.

Acknowledgements: this work was supported, in part, by a grant from Brazilian National Institute of Hormones and Women's Health/Conselho Nacional de Desenvolvimento Científico e Tecnológico [CNPq INCT 573747/2008-3], Brazil.

Disclosure: no potential conflict of interest relevant to this article was reported.

\section{REFERENCES}

1. Azziz R, Woods KS, Reyna R, Key TJ, Knochenhauer ES, Yildiz BO. The prevalence and features of the polycystic ovary syndrome in an unselected population. J Clin Endocrinol Metab. 2004;89:2745-9.

2. Asuncion M, Calvo RM, San Millan JL, Sancho J, Avila S, EscobarMorreale HF. A prospective study of the prevalence of the polycystic ovary syndrome in unselected Caucasian women from Spain. J Clin Endocrinol Metab. 2000;85:2434-8.

3. March WA, Moore VM, Willson KJ, Phillips DI, Norman RJ, Davies MJ.The prevalence of polycystic ovary syndrome in a community sample assessed under contrasting diagnostic criteria. Hum Reprod. 2010;25:544-51.

4. Abbott DH, Tarantal AF, Dmesic DA. Fetal, infant, adolescent and adult phenotypes of polycystic ovary syndrome in prenatally androgenized female rhesus monkeys. Am J Primatol. 2009;71:776-84.

5. Oberfield SE, Sopher AB, Gerken AT. Approach to the girl with early onset of pubic hair. J Clin Endocrinol Metab. 2011;96:1610-22.

6. Zhang HY, Guo CX, Zhu FF, Qu PP, Lin WJ, Xiong J. Clinical characteristics, metabolic features, and phenotype of Chinese women with polycystic ovary syndrome: a large-scale casecontrol study. Arch Gynecol Obstet. 2013;287:525-31.

7. Ferriman D, Gallwey JD. Clinical assessment of body hair growth in women. J Clin Endocrinol Metab. 1961;21:1440-7.

8. Zawadski JF, Dunaif A. Diagnostic criteria for polycystic ovary syndrome: towards a rational approach. In: Dunaif A, Givens JR, Haseltuine F, editors. Polycystic ovary syndrome. Boston: Blackwell Scientific; 1992. p. 377-84.

9. Rotterdam EA-SPCWG. Revised 2003 consensus on diagnostic criteria and long-term health risks related to polycystic ovary syndrome. Fertil Steril. 2004;81:19-25.

10. Azziz R, Carmina E, Dewailly D, Diamanti-Kandarakis E, EscobarMorreale HF, Futterweit W, et al. Androgen Excess Society. Positions statement: criteria for defining polycystic ovary syndrome as a predominantly hyperandrogenic syndrome: an Androgen Excess Society guideline. J Clin Endocrinol Metab. 2006;91:4237-45.

11. Dewailly D, Gronier H, Poncelet E, Robin G, Leroy M, Pigny P, et al. Diagnosis of polycystic ovary syndrome (PCOS): revisiting the threshold values of follicle count on ultrasound and of the serum AMH level for the definition of polycystic ovaries. Hum Reprod. 2011;26:3123-9. 
12. Lujan ME, Jarrett BY, Brooks ED, Reines JK, Peppin AK, Muhn N, et al. Updated ultrasound criteria for polycystic ovary syndrome: reliable thresholds for elevated follicle population and ovarian volume. Hum Reprod. 2013;28:1361-8.

13. Fauser BC, Tarlatzis BC, Rebar RW, Legro RS, Balen AH, Lobo R, et al. Consensus on women's health aspects of Polycystic Ovary Syndrome (PCOS): the Amsterdam ESHRE/ASRM-Sponsered 3rd PCOS Consensus Workshop Group. Fertil Steril. 2012;97:28-38e25.

14. Frajndlich R, Spritzer PM. Association between ovarian volume and serum insulin levels in ovulatory patients with idiopathic hirsutism. Fertil Steril. 2005;83(5):1561-4.

15. NIH. Disease Prevention Evidence-based Methodology Workshop on Polycystic Ovary syndrome. In: NIH Office Disease Prevention Methodology Workshops: National Institutes of Health: Expert Panel Guidelines on PCOS; 2012.

16. Herter LD, Golendziner E, Flores JA, Becker E Jr, Spritzer PM. Ovarian and uterine sonography in healthy girls between 1 and 13 years old: correlation of findings with age and pubertal status. Am J Roentgenol. 2002;178(6):1531-6.

17. Herter LD, Magalhães JA, Spritzer PM. Relevance of the determination of ovarian volume in adolescent girls with menstrual disorders. J Clin Ultrasound. 1996;24(5):243-8.

18. Carmina E, Oberfield SE, Lobo RA. The diagnosis of polycystic ovary syndrome in adolescents. Am J Obstet Gynecol. 2010;203:201.e1-5.

19. Brown ZA, Louwers $Y$ V, Fong SL, Valkenburg O, Birnie E, de Jong $\mathrm{FH}$, et al. The phenotype of polycystic ovary syndrome ameliorates with aging. Fertil Steril. 2011;96(5):1259-65.

20. Davison SL, Bell R, Donath S, Montalto JG, Davis SR. Androgen levels in adult females: changes with age, menopause, and oophorectomy. J Clin Endocrinol Metab. 2005;90(7):3847-53.

21. Carmina E, Campagna AM, Lobo RA. A 20-year follow-up of young women with polycystic ovary syndrome. Obstet Gynecol. 2012;119:263-9.

22. Oppermann K, Fuchs SC, Spritzer PM. Ovarian volume in pre- and perimenopausal women: a population-based study. Menopause. 2003;10:209-13.

23. Apridonidze T, Essah PA, luorno MJ, Nestler JE. Prevalence and characteristics of the metabolic syndrome in women with polycystic ovary syndrome. J Clin Endocrinol Metab. 2005;90:1929-35.

24. de Vries L, Karasik A, Landau Z, Phillip M, Kiviti S, GoldbergStern H. Endocrine effects of valproate in adolescent girls with epilepsy. Epilepsia. 2007;48:470-7.

25. Peppard HR, Marfori J, luorno MJ, Nestler JE. Prevalence of polycystic ovary syndrome among premenopausal women with type 2 diabetes. Diabetes Care. 2001;24:1050-2.

26. Graff SK, Mário FM, Alves BC, Spritzer PM. Dietary glycemic index is associated with less favorable anthropometric and metabolic profile in PCOS women with different phenotypes. Fertil Steril. 2013;100(4):1081-8.

27. Lim SS, Davies MJ, Norman RJ, Moran LJ. Overweight, obesity and central obesity in women with polycystic ovary syndrome: a systematic review and meta-analysis. Hum Reprod Update. 2012;18:618-37.

28. Diamanti-Kandarakis E, Spritzer PM, Sir-Petermann T, Motta AB. Insulin resistance and polycystic ovary syndrome through life. Curr Pharm Des. 2012;18(34):5569-76.

29. Wiltgen D, Spritzer PM. Variation in metabolic and cardiovascular risk in women with different polycystic ovary syndrome phenotypes. Fertil Steril. 2010;94:2493-6.
30. Moran L, Teede H. Metabolic features of the reproductive phenotypes of polycystic ovary syndrome. Hum Reprod Update. 2009;15:477-88.

31. Lecke SB, Morsch DM, Spritzer PM. CYP19 gene expression in subcutaneous adipose tissue is associated with blood pressure in women with polycystic ovary syndrome. Steroids. 2011;76(12):1383-8.

32. Wild RA, Rizzo M, Clifton S, Carmina E. Lipid levels in polycystic ovary syndrome: systematic review and meta-analysis. Fertil Steril. 2011;95:1073-9.e1-11.

33. Di Domenico K, Wiltgen D, Nickel FJ, Magalhães JA, Moraes RS, Spritzer PM. Cardiac autonomic modulation in polycystic ovary syndrome: does the phenotype matter? Fertil Steril. 2013;99(1):286-92.

34. Nácul AP, Andrade CD, Schwartz P, de Bittencourt PI Jr, Spritzer PM. Nitric oxide and fibrinogen in polycystic ovary syndrome: associations with insulin resistance and obesity. Eur J Obstet Gynecol Reprod Biol. 2007;133(2):191-6.

35. Moghetti P, Tosi F, Bonin C, Di Sarra D, Fiers T, Kaufman J, et al. Divergences in insulin resistance between the different phenotypes of the polycystic ovary syndrome. J Clin Endocrinol. 2013;98(4):E628-37.

36. Yildiz BO, Bozdag G, Yapici Z, Esinler I, Yarali H. Prevalence, phenotype and cardiometabolic risk of polycystic ovary syndrome under different diagnostic criteria. Hum Reprod. 2012;27(10):3067-73.

37. Marshall JC, Dunaif A. Should all women with PCOS be treated for insulin resistance? Fertil Steril. 2012;97(1):18-22.

38. Salpeter SR, Buckley NS, Kahn JA, Salpeter EE. Meta-analysis: metformin treatment in persons at risk for diabetes mellitus. Am J Med. 2008;121:149-57.

39. Baillargeon JP, luorno MJ, Nestler JE. Insulin sensitizers for polycystic ovary syndrome. Clin Obstet Gynecol. 2003;46(2): 325-40.

40. Attia GR, RaineyWE, Carr BR. Metformin directly inhibits androgen production in human thecal cells. Fertil Steril. 2001;76(3): 517-24.

41. Nieuwenhuis-Ruifrok $A E$, Kuchenbecker WK, Hoek $A$, Middleton $P$, Norman RJ. Insulin sensitizing drugs for weight loss in women of reproductive age who are overweight or obese: systematic review and meta-analysis. Hum Reprod Update. 2009;15(1):57-68.

42. Glueck CJ, Goldenberg N, Sieve L, Wang P. An observational study of reduction of insulin resistance and prevention of development of type 2 diabetes mellitus in women with polycystic ovary syndrome treated with metformin and diet. Metab Clin Exp. 2008;57(7):954-60.

43. Bargiota A, Diamanti-Kandarakis E. The effects of old, new and emerging medicines on metabolic aberrations in PCOS. Ther Adv Endocrinol Metab. 2012;3(1):27-47.

44. Ladson G, Dodson WC, Sweet SD, Archibong AE, Kunselman AR, Demers $L M$, et al. The effects of metformin with lifestyle therapy in polycystic ovary syndrome: a randomized double-blind study. Fertil Steril. 2011;95(3):1059-66.

45. Costello MF, Shrestha B, Eden J, Johnson NP, Sjoblom P. Metformin versus oral contraceptive pill in polycystic ovary syndrome: a Cochrane review. Human Reprod. 2007;22 (5):1200-9.

46. Gomez-Meade CA, Lopez-Mitnik G, Messiah SE, Arheart KL, Carrillo A, de la Cruz-Muñoz N. Cardiometabolic health among gastric bypass surgery patients with polycystic ovarian syndrome. World J Diabetes. 2013;4(3):64-9. 